\title{
Dinâmica de participação social em Conselho Municipal de Meio Ambiente do Território Açu-Mossoró (RN): A realidade sob o prisma documental
}

Dynamics of social participation in the Municipal Environmental Council of the Açu-Mossoró

Territory (RN): Reality from a documentary perspective

Dinámica de participación social en el Consejo Municipal de Medio Ambiente del Territorio AçuMossoró (RN): Realidad desde una perspectiva documental

\section{Resumo}

O estudo teve como objetivo identificar a dinâmica da participação do ponto de vista formal, investigando o funcionamento do processo de tomada de decisão pela atuação dos conselheiros evidenciada nas atas e resoluções. A abordagem dessa pesquisa se constituiu pelo método qualitativo, pesquisa descritiva e pesquisa documental por se valer de documentos do próprio Conselho Municipal de Defesa do Meio Ambiente (CONDEMA), tais como atas, relatórios e resoluções, cuja análise textual foi feita pela análise interpretativa. A pesquisa documental, obtidas no Projeto SISMUMA, no CONDEMA e no Jornal Oficial de Mossoró, teve como propósito analisar a atuação do CONDEMA sob o ponto de vista legal e formal, como forma de caracterização do arranjo institucional, o funcionamento e as atividades do Conselho. Por fim, o que se observou na dimensão formal, detalhado pela visão dos conselheiros, é que o Conselho apresentou alguns problemas, relacionados a assimetria de informação e participação e a grande quantidade de pautas com assuntos técnicos da gestão, que precisam serem refletidos e fortalecidos no processo decisório participativo, pois tem prejudicado a atuação dos membros dos conselheiros de forma que proporcione uma participação ideal uma vez que existe a tendência a uma participação legitimadora das ações do poder público municipal.

Palavras-chave: Participação; Meio ambiente; Conselhos municipais; Documentos.

\begin{abstract}
The study aimed to identify the dynamics of participation from a formal point of view, investigating the functioning of the decision-making process by the performance of the counselors evidenced in the minutes and resolutions. The approach of this research was constituted by the qualitative method, descriptive research and documentary research because it uses documents from the Municipal Council for the Defense of the Environment (CONDEMA), such as minutes, reports and resolutions, whose textual analysis was made by the interpretative analysis. The documentary research, obtained in the SISMUMA Project, in CONDEMA and in the Official Journal of Mossoró, aimed to analyze the performance of CONDEMA from a legal and formal point of view, as a way of characterizing the institutional arrangement, the functioning and the activities of the Council. Finally, what was observed in the formal dimension, detailed by the view of the board members, is that the Board presented some problems, related to the asymmetry of information and participation and the large number of agendas with technical matters of management, which need to be reflected and strengthened. in the participatory decision-making process, as it has impaired the performance of the members of the councilors in a way that provides an ideal participation since there is a tendency to legitimize participation in the actions of the municipal public power.
\end{abstract}


Keywords: Participation; Environment; Municipal councils; Documents.

\section{Resumen}

El estudio tuvo como objetivo identificar las dinámicas de participación desde un punto de vista formal, investigando el funcionamiento del proceso de toma de decisiones por el desempeño de los consejeros evidenciados en las actas y resoluciones. El enfoque de esta investigación estuvo constituido por el método cualitativo, la investigación descriptiva y la investigación documental porque utiliza documentos del Concejo Municipal de Defensa del Medio Ambiente (CONDEMA), tales como actas, informes y resoluciones, cuyo análisis textual fue realizado por el análisis interpretativo. La investigación documental, obtenida en el Proyecto SISMUMA, en CONDEMA y en el Diario Oficial de Mossoró, tuvo como propósito analizar el desempeño de CONDEMA desde el punto de vista legal y formal, como una forma de caracterizar el ordenamiento institucional, el funcionamiento y las actividades del Consejo. Finalmente, lo que se observó en la dimensión formal, detallado por la visión de los consejeros, es que el Directorio presentó algunos problemas, relacionados con la asimetría de información y participación y la gran cantidad de agendas con materias técnicas de gestión, las cuales deben reflejarse y fortalecerse en la toma de decisiones participativa, ya que ha perjudicado el desempeño de los miembros de los concejales de una manera que brinda una participación ideal ya que existe una tendencia a legitimar la participación en las acciones del poder público municipal.

Palabras clave: Participación; Medio ambiente; Ayuntamientos; Documentos.

\section{Introdução}

A promulgação da Constituição Federal de 1988 (CF/88) trouxe mudanças no âmbito social, dentre essas a criação de espaços de participação da população nas decisões da gestão pública, visando a concretização do exercício da cidadania por meio do controle social, oferecendo para a sociedade a oportunidade de influenciar, controlar, observar e contribuir nas formulações de políticas públicas.

O poder exercido pela sociedade sobre o Estado, preconizando a garantia constitucional da soberania popular e o Estado Democrático de Direito é denominado de Controle Social, consistindo em uma prática de vigilância da sociedade sobre os atos das organizações públicas, o que "implica [ao Poder Público] garantir transparência de suas ações e atos e na institucionalização de canal de participação social, enquanto as organizações privadas estão fortemente orientadas para a preservação e proteção dos interesses corporações (dirigentes e acionistas)" (Matias-Pereira, 2016, p. 55).

No campo público, a sociedade pode exercer o controle sob inúmeras dimensões de atuação do poder público e uma delas é a área ambiental. O meio ambiente foi definido pela Constituição Federal (CF/88) como um direito fundamental (artigo 225), com isso assegurou legalmente o acesso à informação ambiental e a proteção conjunta dos bens ambientais entre os entes federados e a coletividade.

A constitucionalização do direito ao meio ambiente ainda respaldou e fortaleceu o Sistema Nacional do Meio Ambiente (SISNAMA), responsável pela proteção e melhoria da qualidade ambiental, que tem como intuito integrar os órgãos, entidades e Conselhos Ambientais de todos os entes da federação de modo que efetive esse direito.

Contudo, a instituição de conselhos não garante a participação efetiva da sociedade, visto que esses podem se constituir em espaços limitados a legitimação das ações do poder público, quando a participação ali exercida não tem a capacidade de expressar a pluralidade de posições dos vários setores que compõem esse lugar institucional.

Nesse contexto, tem-se a seguinte indagação: Como ocorre a participação ambiental nos conselhos municipais do território Açu-Mossoró?

Assim, este trabalho buscou identificar a dinâmica da participação do ponto de vista formal, investigando o funcionamento do processo de tomada de decisão pela atuação dos conselheiros evidenciada nas atas e resoluções.

\section{Referencial Teórico}

A democracia no Brasil ganhou novos contornos com a Constituição Federal de 1988 (CF/88), uma vez que o país 
vivenciou uma ditadura militar com início no ano 1964 e fim em 1985. O fim do período ditatorial marca o início do período de redemocratização, esse período abriu um espaço institucional que deveria ser ocupado pela população, ou seja, para a representatividade da sociedade por meio da participação popular, que caminhasse para uma coexistência e complementaridade com a democracia representativa, mas a sociedade não estava culturalmente preparada para assumir os contornos das perspectivas de participação, demandando assim um amadurecimento para se alcançar a participação ideal (Garbeline, 2017).

A participação (cidadã, social ou popular), historicamente fruto de movimentos sociais organizados que reivindicam e lutam pela superação da situação de exclusão (econômica, social ou política) e ampliação da cidadania, tem em sua vinculação à ideia de partilhamento de poder, que nem sempre é distribuído ou atende de forma justa as diversidades sociais, culturais, étnicas, etc. dos atores e interesses envolvidos. Nesse contexto a participação tende a configurar-se como uma contradição nos Estados democráticos atuais, uma vez que legalmente todos os cidadãos têm "[...] igualmente acesso à cena pública e, dada a forma das relações socioeconômicas, diferentes grupos sociais são excluídos, não só do mercado de trabalho, mas da própria possibilidade de atuar politicamente" (Rosenfield, 2003, p. 83-84).

A participação social não é um modelo definido ou limitado, existem diversas maneiras, tipos, graus, níveis ou formas atuar no contexto social, assentando-se nas propostas de Eidsvik (1978), Pretty (1995) e International Association for Public Participation - IAPP (2014), os autores apresentam diferentes tipologias e propostas sobre o exercício da participação, consentindo em um ponto em comum quando entendem que ela pode acontecer de maneira ativa (cidadão engajado) ou passiva (cidadão inerte), para tanto dependerá do processo de tomada de decisão e processo democrático adotado pelo Estado.

Eidsvik (1978) apresenta uma tipologia (Quadro 1) de graus de participação pública no processo decisório em cinco dimensões: a informação, a persuasão, a consulta, a parceria e o controle, em que o poder decisório entre as organizações e o público (cidadão) são opostos, conforme se observa abaixo:

Quadro 1 - Uma tipologia de graus de participação pública no processo decisório.

\begin{tabular}{|c|c|c|c|c|}
\hline Informação & Persuasão & Consulta & Parceria & Controle \\
\hline $\begin{array}{l}\text { A decisão é } \\
\text { tomada e o } \\
\text { público é } \\
\text { comunicado a } \\
\text { respeito }\end{array}$ & $\begin{array}{l}\text { A decisão é tomada } \\
\text { e há uma tentativa } \\
\text { de convencimento } \\
\text { do público }\end{array}$ & $\begin{array}{c}\text { O problema é } \\
\text { apresentado, opiniões } \\
\text { são coletadas e a } \\
\text { decisão é tomada }\end{array}$ & $\begin{array}{l}\text { Os limites são } \\
\text { previamente } \\
\text { definidos; as } \\
\text { informações são } \\
\text { partilhadas e a } \\
\text { decisão é conjunta }\end{array}$ & $\begin{array}{c}\text { A decisão é } \\
\text { tomada pelo } \\
\text { público, que } \\
\text { assume a } \\
\text { responsabilidade } \\
\text { pública }\end{array}$ \\
\hline
\end{tabular}

Fonte: Eidsvik (1978) (Adaptada).

Pretty (1995), por sua vez, estabeleceu 7 (sete) tipologias de como as pessoas participam no desenvolvimento de programas e projetos, descrevendo também o grau de envolvimento popular na tomada de decisão de cada tipologia, que parte de um tipo de participação mais passiva (manipulada) para outra mais ativa (com grande mobilização), conforme se observa no Quadro 2: 
Quadro 2 - Tipologias de participação.

\begin{tabular}{|c|c|c|}
\hline \multicolumn{2}{|r|}{ Tipologia } & $\begin{array}{l}\text { Características } \\
\end{array}$ \\
\hline 1 & $\begin{array}{l}\text { Participação simulada (ou } \\
\text { manipulada) }\end{array}$ & $\begin{array}{l}\text { A participação é simplesmente um pretexto, embora exista os } \\
\text { representantes "do povo" em quadros de oficiais, as pessoas não tem } \\
\text { direito a votos. }\end{array}$ \\
\hline 2 & Participação passiva & $\begin{array}{l}\text { Nesse caso o processo de decisão é unilateral. As decisões são tomadas } \\
\text { pela administração (ou direção), sem qualquer participação da } \\
\text { comunidade, que apenas recebem as informações do que está em decisão } \\
\text { ou já foi decidido. }\end{array}$ \\
\hline 3 & Participação por consulta & $\begin{array}{l}\text { Nesse processo não há participação popular direta no processo de } \\
\text { tomada de decisão. As pessoas participam sendo consultadas ou } \\
\text { respondendo perguntas (questionário). Os agentes externos é quem } \\
\text { definem os problemas, processos de coleta e análise das informações. }\end{array}$ \\
\hline 4 & $\begin{array}{l}\text { Participação pelos } \\
\text { incentivos materiais }\end{array}$ & $\begin{array}{l}\text { A participação ocorrer por meio de estímulos de recebimento de } \\
\text { incentivos materiais (dinheiro, alimentos, outros produtos ou recursos) } \\
\text { pela contribuição à pesquisa. Porém, com o fim do benefício ocorrerá } \\
\text { perdas no processo de participação. }\end{array}$ \\
\hline 5 & Participação funcional & $\begin{array}{l}\text { As pessoas podem participar formando grupos para atender a objetivos } \\
\text { predeterminados e relacionados com o projeto. O envolvimento popular } \\
\text { é realizado com os administradores (dirigentes ou técnicos). Esse } \\
\text { processo de participação pode ser interativo e envolver os grupos nas } \\
\text { discussões da tomada de decisão dos objetivos, porém as decisões mais } \\
\text { importantes e final é realizada pelos administradores. }\end{array}$ \\
\hline 6 & Participação interativa & $\begin{array}{l}\text { A participação é vista como um direito, e não apenas meios para atingir } \\
\text { determinados requisitos ou objetivos. Esse tipo de participação é o mais } \\
\text { ativo, posto que as pessoas interagem em todo o processo de tomada de } \\
\text { decisão, desde a fase de análise, desenvolvimentos dos planos de ação } \\
\text { até a definição final do projeto. } \\
\text { O processo envolve metodologias interdisciplinares que procuram } \\
\text { múltiplas perspectivas e fazem uso de processos de aprendizagem, } \\
\text { sistêmico e estruturado. A população passa a assumir o controle sobre as } \\
\text { decisões locais e determinar como os recursos disponíveis serão } \\
\text { utilizados, o que possibilita que eles tenham uma participação na } \\
\text { manutenção de estruturas ou práticas. }\end{array}$ \\
\hline 7 & $\begin{array}{l}\text { Auto-mobilização (ou } \\
\text { participação pela } \\
\text { mobilização da } \\
\text { comunidade) }\end{array}$ & $\begin{array}{l}\text { As pessoas participam tomando iniciativas independentemente de } \\
\text { instituições externas para mudar os sistemas. Por meio da iniciativa da } \\
\text { comunidade o processo de discussão sobre os problemas que afetam } \\
\text { aquele grupo pode ocorrer através de contatos com instituições externas } \\
\text { para recursos e assessoria técnica de que necessitam, porém a } \\
\text { comunidade mantém o controle sobre como os recursos serão utilizados. } \\
\text { Auto-mobilização pode se espalhar caso os governos e as ONGs } \\
\text { forneçam um quadro que permita de apoio e parceria com as iniciativas } \\
\text { das comunidades. }\end{array}$ \\
\hline
\end{tabular}

Fonte: Pretty (1995) (Adaptado).

A participação social, após a década de 1990, ganhou ascensão e destaque no campo político, e tem sido traduzida pela exigência legal da sociedade interferir e redirecionar os processos de gestão pública, havendo o estabelecimento de novas relações entre Estado e sociedade, surgindo uma nova concepção de governança, empowerment e accontability com a crescente participação pública, conforme demonstra o grupo da International Association for Public Participation (IAPP) no Quadro 3: 
Quadro 3 - Espectro de participação pública da IAPP.

\begin{tabular}{|c|c|c|c|c|c|}
\hline & \multicolumn{5}{|c|}{ Nível crescente de influência da participação pública } \\
\hline & INFORMAR & CONSULTAR & ENVOLVER & COLABORAR & $\begin{array}{l}\text { EMPODERAR } \\
\text { OU DELEGAR }\end{array}$ \\
\hline $\begin{array}{l}\text { Objetivo de } \\
\text { participação } \\
\text { pública }\end{array}$ & $\begin{array}{ll}\begin{array}{l}\text { Apresentar } \\
\text { informações } \\
\text { objetiva }\end{array} \\
\text { balanceada } & \\
\text { para ajudar } & \text { o } \\
\text { público } & \text { a } \\
\text { entender } \quad \text { o } & \\
\text { problema, suas } \\
\text { alternativas, } \\
\text { oportunidades } \\
\text { e/ou soluções }\end{array}$ & $\begin{array}{l}\text { Obter retorno } \\
\text { do público } \\
\text { sobre análises, } \\
\text { alternativas } \\
\text { e/ou decisões }\end{array}$ & $\begin{array}{l}\text { Trabalhar } \\
\text { diretamente com } \\
\text { o público para } \\
\text { garantir que } \\
\text { preocupações e } \\
\text { aspirações } \\
\text { sejam } \\
\text { constantemente } \\
\text { compreendidas } \\
\text { e consideradas }\end{array}$ & $\begin{array}{l}\text { Estabelecer } \\
\text { parcerias com o } \\
\text { público em cada } \\
\text { aspecto } \\
\text { decisão, } \\
\text { incluindo } \\
\text { proposição de } \\
\text { alternativas e a } \\
\text { identificação da } \\
\text { solução } \\
\text { preferida. }\end{array}$ & $\begin{array}{l}\text { Colocar a } \\
\text { decisão final nas } \\
\text { mãos do público }\end{array}$ \\
\hline $\begin{array}{c}\text { O que se } \\
\text { promete ao } \\
\text { público }\end{array}$ & $\begin{array}{l}\text { Manter } \\
\text { informado }\end{array}$ & 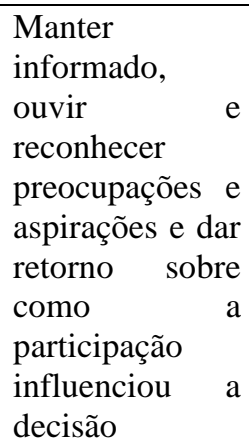 & $\begin{array}{lr}\text { Trabalhar } & \text { em } \\
\text { conjunto } & \text { para } \\
\text { garantir } & \text { que } \\
\text { preocupações } & \mathrm{e} \\
\text { aspirações } & \mathrm{se} \\
\text { reflitam } & \text { nas } \\
\text { alternativas } & \mathrm{e} \\
\text { dar retorno } & \end{array}$ & $\begin{array}{lr}\text { Solicitar } & \\
\text { conselhos } & \text { na } \\
\text { formulação } & \text { de } \\
\text { soluções } & \text { e } \\
\text { incorporá-los às } \\
\text { decisões na } \\
\text { maior medida } \\
\text { possível }\end{array}$ & $\begin{array}{l}\text { Implementar o } \\
\text { que o público } \\
\text { decidir }\end{array}$ \\
\hline
\end{tabular}

Fonte: International Association for Public Participation (2014) (Adaptado).

As tipologias apresentadas têm em comum que a participação é efetiva quando o poder de decisão está efetivamente sob o controle do cidadão. A expansão da participação popular no Brasil tem caminhado para a sua institucionalização, em que "[...] o Estado reconhece a organização popular como força social específica, e o relacionamento entre o Estado e os cidadãos torna-se direito e cotidiano" (Soares, 1992, p. 79), oferecendo um critério objetivo a essa participação com o intuito de inibir as vontades privadas dos administradores (governantes) de forma que essas não prevaleçam sobre aquelas pretendidas pela sociedade e assim buscando diminuir os parâmetros clientelistas que perduram na política brasileira.

\section{Metodologia}

O presente trabalho é uma parte dos resultados da pesquisa intitulada "Conselhos Ambientais: Uma análise do processo de participação de conselheiros municipais no Território Açu-Mossoró-RN” (Morais, 2017), aprovado pelo parecer CAAE n ${ }^{\circ}$ 54041416.1.0000.5294 do Comitê de Ética e Pesquisa (CEP) e Comissão Nacional de Ética em Pesquisa (CONEP), que tinha como objetivo identificar o processo de participação social ambiental em um Conselho do Território Açu-MossoróRN, fazendo por meio de uma abordagem multi-métodos (triangulação) em três dimensões: A primeira em pesquisa de interpretação da lei, compreende a institucionalização da participação, sob o ponto de vista legal, ao analisar as instituições e as normas que regem a participação e a política ambiental. A segunda em uma pesquisa documental identificando, do ponto de vista formal, o funcionamento do processo de tomada de decisão pela participação dos conselheiros evidenciada nos documentos (atas e resoluções). E a terceira, em uma pesquisa de campo que contempla as percepções dos conselheiros sobre a participação considerando a interpretação dos discursos desses entrevistados.

Portanto, este artigo apresenta os resultados da pesquisa que estudou a participação sobre o aspecto formal (segunda dimensão), para tanto utilizou como método de abordagem a pesquisa qualitativa, com finalidade investigativa (Creswell, 
2010), descritiva e por meio da técnica de levantamento de dado da pesquisa documental com fontes de primeira e segunda mão (Vergara, 2016), se valendo de documentos do próprio Conselho e de órgãos públicos.

O recorte espacial da pesquisa se constitui no território Açu-Mossoró (RN), com área de 8.105,10 km² e população de 455.521 habitantes distribuída em 14 municípios (Alto do Rodrigues, Areia Branca, Açu, Carnaubais, Grossos, Ipanguaçu, Itajá, Mossoró, Pendências, Porto do Mangue, São Rafael, Tibau, Baraúna e Serra do Mel) (MDA, SIT, 2014).

Figura 1 - Território Açu-Mossoró (RN).

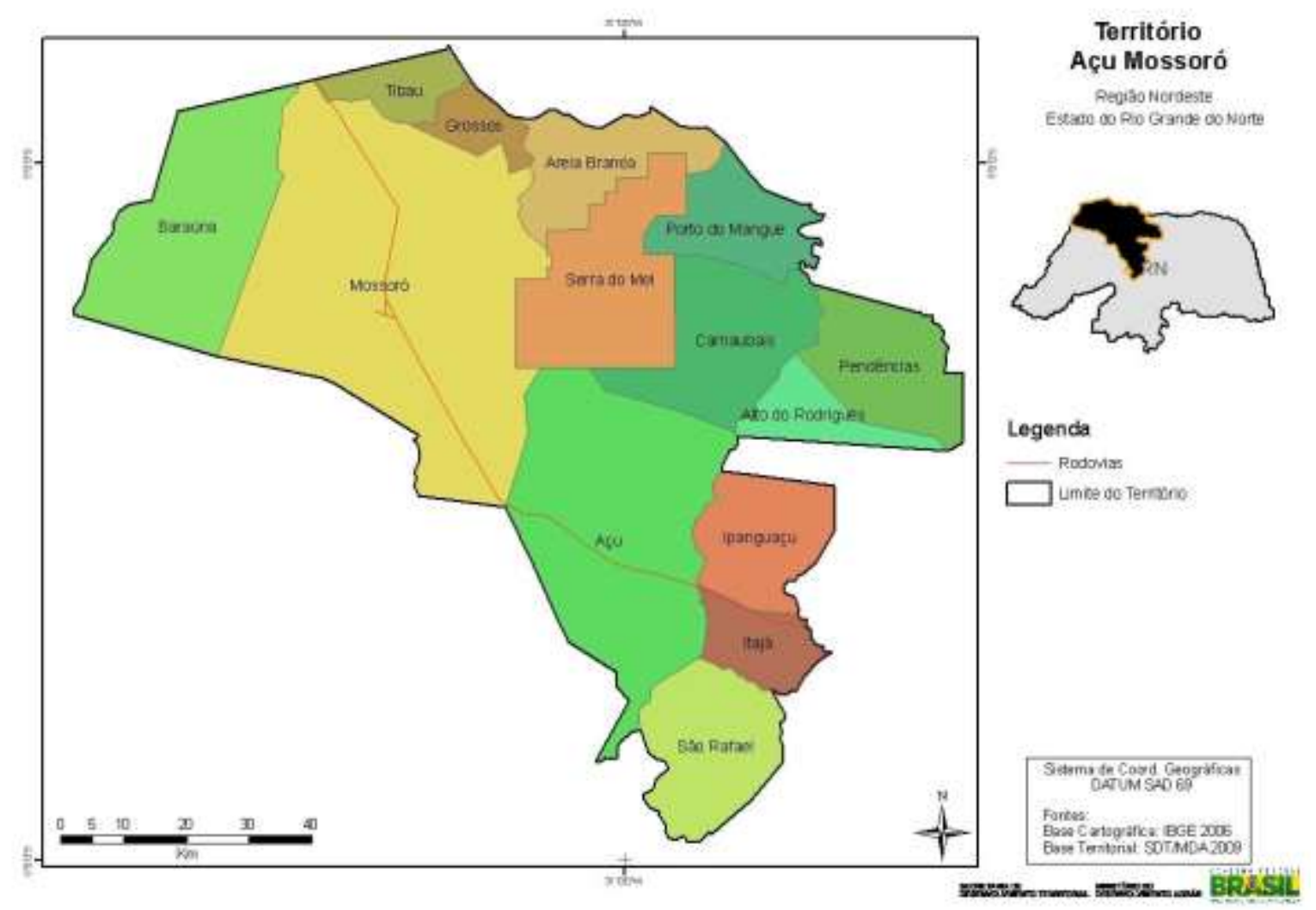

Fonte: MDA, SIT (2014).

Para a pesquisa classificou-se as situações dos Conselhos em ativos, inativos e inexistentes. Após mapeamento da situação dos Conselhos de Meio Ambiente nos municípios do Território Açu-Mossoró-RN, haviam seis municípios com Conselhos inativos, sete em que não existiam Conselhos e apenas o município de Mossoró possuía Conselho ativo e com atividades em funcionamentos. Sendo este o critério adotado para se realizar a investigação e análise sobre a participação.

As informações documentais foram obtidas no Projeto SISMUMA, Jornal Oficial de Mossoró e no CONDEMA, que assim foram materializados:

O Projeto Sistema Municipal de Meio Ambiente (SISMUMA), do Instituto de Desenvolvimento Sustentável e Meio Ambiente do Rio Grande do Norte (IDEMA), apresentou o documento intitulado de "Relatório Parcial do Diagnóstico sobre os Sistemas Municipais de Meio Ambiente do Estado do Rio Grande do Norte (2014)" contendo um panorama geral dos Conselhos no Estado.

No Jornal Oficial de Mossoró, analisando as legislações ambientais e publicações do Conselho, avaliando da Edição 01 de 30 de janeiro de 2008 a Edição 389 de 31 de dezembro de 2016. Nessa pesquisa foram utilizados os termos "ambiental", "meio ambiente", "conselho" e "CONDEMA" para localizar os documentos e normas que tratavam da regulamentação ambiental do município.

No Conselho Municipal de Defesa do Meio Ambiente (CONDEMA) obteve-se projetos de lei, resoluções, ofícios, 
informativos, pareceres, atas de reuniões, regimento interno, relatórios e demais documentos necessários para complementar os dados e permitir a contextualização das informações sobre o tema da pesquisa.

$\mathrm{O}$ acesso aos documentos ocorreu por meio de solicitação formal ao Gerente do Meio Ambiente do município, que autorizou a fotocópia pela Carta de Anuência n ${ }^{\circ}$ 012/2016 da Secretária Executiva de Meio Ambiente. Desse modo, foi feita a leitura e análise de 34 (trinta e quatro) atas de reuniões ordinárias, 7 (sete) atas de reuniões extraordinárias e 13 (treze) resoluções abrangidas nos períodos de início da atuação do CONDEMA no ano 2009 até o prazo fim da pesquisa (no ano de 2015).

A pesquisa documental teve como propósito analisar a atuação do conselho Municipal de Defesa do Meio Ambiente (CONDEMA) sob o ponto de vista legal e formal, como forma de caracterização do arranjo institucional, o funcionamento e as atividades do Conselho.

A análise e tratamento desses dados foi realizada pela análise textual, temática e interpretativa (Severino, 2013):

Figura 2 - Sistematização da Análise Textual, Temática e Interpretativa.

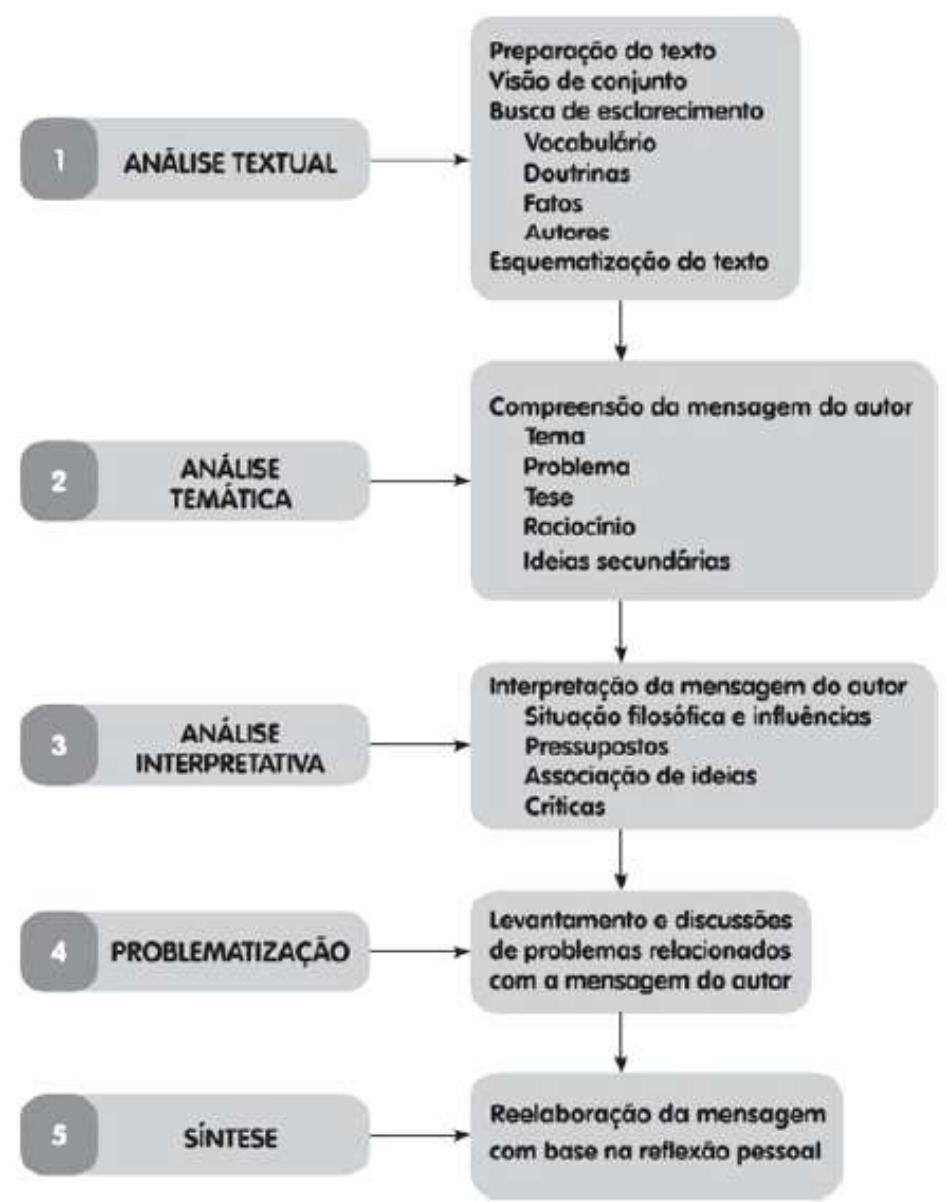

Fonte: Severino (2013, p. 55).

Na primeira etapa (análise textual) foi feito uma preparação dos textos, com leitura de visão de conjunto, buscando nesse momento o esclarecimento relativo aos produtores dos discursos (textos), ao vocabulário específico, aos fatos, doutrinas e autores citados, que sejam importantes para a compreensão dos discursos produzidos nos documentos.

$\mathrm{Na}$ segunda etapa (análise temática) procurou estabelecer a compreensão das mensagens dos autores dos discursos lidos, determinando o tema-problema, a ideia central e as ideias secundárias e reconstruindo o processo lógico do pensamento dos autores dos discursos, evidenciando e esquematizando estrutura lógica do texto documental e das sequências das ideias. 
$\mathrm{Na}$ terceira etapa (análise interpretativa) foi feita a interpretação do texto, situando os textos no contexto de sua produção, assim como no contexto cultural, social e histórico, levando em consideração os pressupostos teóricos, filosóficos e ideológicos que justifiquem as posturas dos produtores daqueles discursos, além de aproximar e associar ideias desses autores do discurso com outras ideias relacionadas à mesma temática. Para isso foi exercido uma atitude crítica diante das posições dos discursos dos conselheiros em termos de: “a) coerência interna da argumentação; b) validade dos argumentos empregados; c) originalidade do tratamento dado ao problema; d) profundidade de análise ao tema; d) alcance de suas conclusões e consequências; e) apreciação e juízo pessoal das ideias defendidas" (Severino, 2013, p. 55).

Por fim, o levantamento e discussões de problemas relacionados com os discursos dos conselheiros nos documentos são problematizados com o debate de questões explícitas ou implícitas no texto, resultando no desenvolvimento de mensagem mediante retomada pessoal do texto e raciocínio personalizado, com a elaboração de um novo texto, com redação própria, com discussão e reflexão pessoais necessária para compreender da participação sob o prisma dos documentos (ponto de vista formal), ao caracterizar os assuntos/temas abordados, as frequências e a atuação histórica dos Conselho e seus membros desde o surgimento até o estágio final da pesquisa.

\section{Resultados e Discussão}

A participação não está somente relacionada à existência de instituições e/ou mecanismos, mas como incidem os processos de tomadas de decisões e a ocorrência de reuniões que resultem em ações que interfiram na esfera real e gerem impactos positivos nas políticas e/ou gestão ambiental.

O equilíbrio de poder, as frequências de reuniões e a participação dos membros de forma simétrica são condições essenciais para a garantia da pluralidade e legitimidade do processo. Em termos legais o CONDEMA de Mossoró possui equilíbrio na sua composição, visto que o número de participantes é plural e paritário, cujo quantitativo de conselheiros proporciona equilíbrio entre Estado e Sociedade no processo decisório.

Para compreender o processo de participação, os documentos analisados foram as resoluções emitidas pelo CONDEMA e as atas das reuniões realizadas.

\subsection{Resoluções do CONDEMA de Mossoró/RN (2009-2015)}

As resoluções configuram-se como normas jurídicas com o propósito de auxiliar o poder executivo na gestão pública, portanto, são atos administrativos, da espécie normativa, que contêm determinações gerais e abstratas com conteúdo análogo ao das leis, visando sua correta aplicação.

As resoluções enquanto atos administrativos normativos não podem inovar o ordenamento jurídico, ou seja, criar direitos e obrigações para os administrados. Cabendo às resoluções disciplinarem assuntos de sua competência específica, ao explicar os regulamentos e os regimentos de determinada matéria exclusiva, podendo produzir efeitos externos. Contudo os atos normativos podem detalhar, explicitar o conteúdo das leis que regulamentam (Carvalho Filho, 2020).

Analisando e fazendo um levantamento das resoluções promovidas e aprovadas pelo CONDEMA de Mossoró/RN entre os períodos de 2009 a 2015, têm-se a produção de 13 Resoluções que tematizam uma conduta em defesa e na promoção do meio ambiente.

O período compreendido entre os anos de 2009 a 2011 foi o que mais houve atuação do CONDEMA no estabelecimento de resoluções. Quanto ao teor das resoluções aprovadas pode-se observar no Quadro 4, de acordo com o número de ordem, ano e o conteúdo dessa norma: 
Quadro 4 - Resoluções aprovadas pelo CONDEMA de Mossoró/RN (2009-2015).

\begin{tabular}{|c|c|c|}
\hline RESOLUÇÃO & ANO & CONTEÚDO \\
\hline 01 & 2009 & $\begin{array}{l}\text { Sem informações - Não foi encontrado a resolução nos documentos do conselho e } \\
\text { não foi publicado no Diário Oficial do Município. }\end{array}$ \\
\hline 02 & 2009 & $\begin{array}{l}\text { Dispõe sobre preços, classificação e enquadramento de atividades e dá outras } \\
\text { providências para o licenciamento ambiental no Município de Mossoró-RN. }\end{array}$ \\
\hline 03 & 2009 & $\begin{array}{l}\text { Dispõe sobre enquadramento das atividades de comércio varejista de produtos } \\
\text { veterinários, agroquímicos e agropecuários e o descarte final de embalagens desses } \\
\text { produtos para fins de licenciamento ambiental no Município de Mossoró-RN. }\end{array}$ \\
\hline 04 & 2009 & $\begin{array}{l}\text { Dispõe sobre preços, classificação e enquadramento de atividades e dá outras } \\
\text { providências para o licenciamento ambiental no Município de Mossoró-RN. }\end{array}$ \\
\hline 05 & 2010 & $\begin{array}{l}\text { Dispõe sobre o Plano de Controle da Poluição de Veículos - PCPV no âmbito do } \\
\text { município de Mossoró-RN. }\end{array}$ \\
\hline 06 & 2010 & Dispõe sobre ruídos urbanos, proteção do bem estar e do sossego público. \\
\hline 07 & 2010 & $\begin{array}{l}\text { Dispõe sobre adequações no enquadramento de atividades para fins de } \\
\text { Licenciamento Ambiental e dá outras providências para o licenciamento ambiental } \\
\text { no Município de Mossoró-RN. }\end{array}$ \\
\hline 08 & 2010 & $\begin{array}{l}\text { Dispõe sobre preços, classificação e enquadramento de atividades e dá outras } \\
\text { providências para o licenciamento ambiental no Município de Mossoró }\end{array}$ \\
\hline 09 & 2011 & $\begin{array}{l}\text { Estabelece que a Dispensa de Licença } \text { (DL) será concedida aos } \\
\text { empreendimentos/atividade que não possuam enquadramento específico, de micro } \\
\text { porte e que apresente potencial poluidor/degradador irrelevante. }\end{array}$ \\
\hline 010 & 2011 & $\begin{array}{l}\text { Altera o art. } 3^{\circ} \text { da Resolução CONDEMA } 007 / 09 \text { que dispõe sobre classificação e } \\
\text { enquadramento de atividades e dá outras providências para o licenciamento } \\
\text { ambiental no Município de Mossoró-RN. }\end{array}$ \\
\hline 011 & 2011 & $\begin{array}{l}\text { Dispõe sobre as normas e procedimentos para execução do disposto na Lei } \\
2.678 / 10 \text {. }\end{array}$ \\
\hline 012 & 2011 & $\begin{array}{l}\text { Dispõe a regulamentação da compensação ambiental nos termos da Lei } \\
\text { Complementar 026/2008. }\end{array}$ \\
\hline 013 & 2014 & Institui o calendário de Reuniões Ordinárias do CONDEMA para o ano de 2014. \\
\hline
\end{tabular}

Fonte: Autores, a partir das resoluções informadas pelo CONDEMA e publicadas no Jornal Oficial de Mossoró.

Considerando o objeto das resoluções observa-se que a contribuição da participação dos conselheiros em grande parte das resoluções oriundas do CONDEMA de Mossoró foi restrita a proposições de esclarecimentos e de reforço as pautas de questões setoriais específicas e pontuais de assuntos da gestão em detrimento de proposições de políticas que evidenciasse o norteamento ambiental da atuação pública, o que se chama de "tecnificação da política" (Acselrad, 1996; Cohn, 2009). A participação voltada para a legitimação (regulamentação) de legislação ou decisões da gestão de forma que "[...] a técnica faz que questões políticas e estratégias sejam (falsamente) reduzidas a debates sobre qual a alternativa técnica viável ou mais eficiente, mascarando os interesses sociais distintos, de caráter subjetivo e passível de decisão política (e não técnica)" (Fonseca, Bursztyn \& Moura, 2012, p. 186).

\subsection{Atas das reuniões do CONDEMA}

No estudo de todas as atas das reuniões é possível analisar formalmente o processo participativo dos conselheiros nas tomadas de decisões ambientais, bem como as ações do CONDEMA na defesa, proteção e promoção do meio ambiente no município de Mossoró. Nesse sentido foi feita uma leitura minuciosa de todas as atas, e após isso uma análise com destaques dos principais pontos que tangenciam a participações dos membros nas questões ambientais.

\subsubsection{Período 2009-2012}

No ano de 2009 foram realizadas 11 reuniões, sendo oito ordinárias e três extraordinárias. Os dados revelam que somente na primeira reunião ordinária não houve quórum, porém, o presidente do conselho propôs que este encontro fosse 
realizado em caráter ad referendum. Em todas as reuniões a figura do presidente se torna protagonista, ao trazer as principais demandas para serem apreciadas e votadas, nesse ano de 2009 a maioria das demandas do conselho foram estratégicas, visto que as decisões ocorreram em torno das regulamentações do processo licitatório do município, apreciações de minutas de leis e resoluções de questões ambientais. Já as decisões operacionais tinham a intenção de cumprir as pendências de institucionalização do conselho.

Nas diversas atuações dos conselheiros, destaca-se a apreciação da proposta da Resolução $n^{\circ}$ 02/2009 que trata da incorporação de outras atividades/empreendimentos para fins de licenciamento ambiental, ocorrida na segunda reunião ordinária, havendo questionamento de conselheiros representantes do poder público e da sociedade civil sobre os valores estabelecidos para dispensa, como se vê: O representante da UERN [representante da sociedade civil] nesse questionou sobre a forma usada para alcançar os valores
estabelecidos para as licenças ambientais, sendo respondido pelo presidente que os valores têm como base os parâmetros
adotados pelo IDEMA, acrescidos de cem reais para cobrir custos com publicação no Jornal Oficial de Mossoró. O representante
da UERN questionou então no caso de haver a publicação do pedido de licença, a quem deverá ser atribuído a
responsabilidade, pois em nenhum momento fica claro essa questão, o que foi de pronto respondido pelo presidente que a
responsabilidade será sempre do órgão licenciador. A promotoria [representante do poder público] então questionou que como
estão colocados os valores, fica caracterizado como tributo. O presidente propôs encaminhar a questão para consulta a
Procuradoria Geral do município para que seja resguardada de contestações posteriores. Ressaltou ainda que trinta por cento dos
recursos arrecadados com o licenciamento serão destinados ao Fundo Municipal de Meio Ambiente, dos quais, quinze por cento
serão destinados as ações de Educação Ambiental (Ata da Segunda Sessão Ordinária do CONDEMA, linhas 41-52).

É possível observar que nessa reunião houve a participação dos membros de ambas as representações no processo de tomada de decisão, apresentando informações, que se não levada em consideração, influenciariam negativamente na aplicação da norma em comento. O processo participativo tem efeito quando se é levado em conta os anseios e as falas dos seus membros, de modo que se é esclarecido e debatido, e por fim solucionado qualquer celeuma, nesse caso o presidente procurou dirimir os questionamentos e quando não claros determinou o auxílio de outro órgão para tomar uma decisão final de forma coletiva, configurando o que Eidsvik (1978) denominou de parceria.

A participação como parceria (Eidsvik, 1978) também ocorre no ano de 2009 quando uma demanda foi apresentada pelo conselheiro representante do poder público que foi a proposta de "minuta de lei sobre ruídos urbanos, proteção do bem estar e do sossego público", sendo apreciada pelos membros do Conselho, ocasião em que dois membros representantes da sociedade civil sugeriram mudanças no texto da lei, sendo acatadas pelos membros do Conselho.

Outro ponto de destaque da participação dos membros nas decisões para preservação e promoção ambiental no município, ocorreu na quarta reunião ordinária, com a apresentação, pelo conselheiro representante do IBAMA, da proposta oriunda do Instituto Chico Mendes de Conservação da Biodiversidade (ICMBio) sobre o projeto de criação da Unidade de Conservação no assentamento Eldorado dos Carajás II (antiga área da fazenda Maísa) entre os municípios de Mossoró e Baraúna, área que possui as maiores cavernas do Estado, além de vegetação bem preservada com potencial para Unidade de Conservação Territorial.

Nesse sentido, foi solicitado parecer favorável do CONDEMA para implantação do projeto, o presidente, por sua vez, solicitou apresentação e estudos técnicos do IBAMA, posicionamento de representante do município de Baraúna e do departamento de Geologia da UERN, para que tivessem elementos suficientes para apreciação e aprovação de minuta de lei para envio aos poderes legislativo e executivo.

O desfecho dessa demanda ocorreu na quinta reunião, em que foi apresentado o trabalho do Biólogo e Analista Ambiental convidado sobre a Unidade de Conservação Parque Nacional Complexo Espeleológico Furna Feia (BRASIL, 2012), proposta essa que foi sugerida na quarta reunião ordinária do CONDEMA, o ambientalista apresentou elementos técnicoscientíficos para apoio do Conselho ao projeto, dentre os diversos apresentados, os principais foram que: 
[...] esta é uma das maiores áreas de reserva legal do estado, com proposta de criação de Unidade de Conservação do Rio Grande do Norte, e um dos maiores remanescentes do bioma caatinga do estado, único bioma exclusivamente brasileiro com fauna e flora bem preservados. De acordo com a apresentação [do ambientalista] com base em dados do CECAV-ICMBIO há na área 51 cavernas, entre elas a Furna Feia, maior caverna do Estado. [O ambientalista] argumentou que um dos principais pontos favoráveis à criação da Unidade de Conservação, é a relevância do patrimônio espeleológico encontrado na área, e que a Furna Feia é hoje integrante do patrimônio cultural, histórico, geográfico, natural, paisagístico e ambiental do Estado. Observou ainda que a criação do parque nacional deve ser priorizado uma vez que a visitação desordenada à área, as pichações, a presença de lixo, caça predatória e a retirada da madeira nativa, veem gerando impactos negativos a área, e reforçando que esta seria a primeira Unidade de Conservação no Estado com cavernas. O ambientalista concluiu sua apresentação solicitando apoio ao projeto de criação da Unidade de Conservação, por parte do Poder Público, representantes de associações de classe, de entidades civis e instituições superiores (Ata da Quinta Reunião Ordinária do CONDEMA, linhas 87-105).

Diante da explanação e apresentação dos elementos para o apoio do CONDEMA na criação da Unidade de Conservação, os membros acataram os elementos apresentados e manifestaram seus apoios à criação, desta forma o presidente sugeriu o envio de uma Carta de Apoio por parte das entidades representadas no Conselho e uma Carta de Apoio do CONDEMA ao projeto com a assinatura de todos os conselheiros ambientais. Uma conquista importante no sentido da participação da sociedade civil, uma vez que essa demanda não partiu do poder público, mas ganhou atenção e espaço nas discussões do Conselho, configurando a participação classificada em parceria (Eidsvik, 1978), interativa (Pretty, 1995) e do tipo colaborar (IDPP, 2014).

A colaboração do CONDEMA com outras instituições e entidades que buscam a proteção e o desenvolvimento socioambiental local é um dos componentes essenciais para o processo participativo democrático e efetividade das decisões do Conselho na gestão ambiental local.

Em termos gerais a maioria dos assuntos das pautas apreciadas e as decisões derivadas tinham características estratégicas, o Conselho nesse primeiro ano de atuação funcionou legitimando das decisões do governo, embora algumas vezes os membros tenham se posicionado de forma crítica a alguns assuntos, conforme o destaque acima da questão do licenciamento ambiental.

A participação dos membros ocorreu algumas vezes de forma propositiva, configurando nos tipos parceria (Eidsvik, 1978), interativa (Pretty, 1995) e de colaborar (IDPP, 2014), quando estes apresentavam demandas para apreciação do conselho, como exemplo na quinta reunião ordinária em que a conselheira representante da sociedade civil informou sobre o projeto de criação de um Centro de Triagem para reciclagem do lixo urbano de Mossoró, da Associação Reciclando para a Vida (ACREVI), solicitando ampliação da área e agilidade ao projeto, que em discussão entre os membros ficou estabelecido o envio de documento com os pontos discutidos em reunião sobre a temática a câmara municipal, sendo acatado por todos os conselheiros.

E outras vezes a participação ocorria de forma consultiva (Eidsvik, 1978; IAPP, 2014) ou funcional (Pretty, 1995) geralmente quando o presidente apresentava as minutas de leis, resoluções e demandas institucionais do governo para obter retorno dos conselheiros pela coleta de opiniões e sugestões para posteriormente ser domada a decisão.

Em 2009 existiu uma preponderância, em quatro reuniões, de participantes do poder público em detrimento da sociedade civil. Em outras quatro houve igualdade de membros participantes e em apenas duas reuniões teve mais representantes da sociedade civil em relação ao do poder público. A frequência mais assídua dos representantes do poder público nesse primeiro ano pode estar ligada com a mobilização da gestão para resolução de suas demandas na área ambiental.

A menor frequência dos representantes da sociedade civil representa uma participação fraca e/ou submissa, (Nunes, Philippi Jr. \& Fernandes, 2012), que pode ser justificada pela falta de engajamento político e interesse dos representantes da sociedade, ou então dificuldades relativas a disponibilidade, uma vez que as atividades dos membros do conselho se torna onerosa para os participantes da sociedade civil, pois não são remunerados e nem dispensados dos serviços de origens, em 
contrapartida a maioria dos representantes do poder público não assumem os custos para o exercício participativo no CONDEMA.

No ano de 2010 foram realizadas apenas seis reuniões ordinárias, semelhante ao que acontecia no ano anterior, a figura central na proposição da atividade do conselho residia no presidente, as caracterizações das demanda do Conselho foram eminentemente estratégicas, com ênfase na produção legislativa para regulamentação de atividades ambientais e o licenciamento ambiental no município, além de apresentarem para o Conselho as atividades administrativas do Departamento de Gerência Ambiental.

Nesse ano é possível destacar como um ganho da participação no CONDEMA e para o incentivo da defesa do meio ambiente a formalização da composição da câmara técnica do Fundo Municipal de Meio Ambiente (FUNAM), que buscou o direcionamento de fundos financeiros para o exercício das atividades em prol do meio ambiente no município.

$\mathrm{Na}$ décima reunião ordinária um dos destaques sobre o processo participativo é a menção sobre uma possível capacitação dos conselheiros que ocorreria em um evento realizado pela Gerência Executiva da Gestão Ambiental.

A capacitação, qualificação e educação continuada é fundamental para o exercício de uma participação efetiva, uma vez que só se controla aquilo que se conhece (Cotta, Cazal \& Rodrigues, 2009), considerando especialmente as características dos conselhos de temática ambiental, por ser um espaço que necessita que seus membros sejam dotados de informações e conhecimentos técnicos e políticos como elemento essencial para relações simétricas nos processos de tomada de decisões (Souza \& Novicki, 2010, 2011; Nunes, Philippi Jr. \& Fernandes, 2012; Pereira, Lima \& Martins, 2013).

Os conselheiros, assim como no ano anterior, atuaram algumas vezes de forma crítica e propositiva, classificada no tipo de parceria (Eidsvik, 1978), interativa (Pretty, 1995) e de colaborar (IDPP, 2014). De maneira crítica temos a situação que ocorreu na décima quarta reunião ordinária em apreciação e aprovação da Resolução CONDEMA nº 008/2010 sobre preços públicos, classificação e enquadramento de atividades para o licenciamento ambiental no município, oportunidade em que o conselheiro representante da sociedade civil questionou a aplicação da resolução sob uma situação de licença permanente.

Geralmente os questionamentos dos conselheiros sobre situações e assuntos específicos tratados no âmbito do CONDEMA são prontamente respondidos pelo presidente, por vezes essa arena participativa funciona como uma plataforma de ações governamentais em que os assuntos, dúvidas e questionamentos são justificados/defendidos pelo presidente sem uma discussão e reflexão sobre o assunto, assim a participação crítica depois do questionamento e esclarecimento, se torna uma participação informativa (Eidsvik, 1978; IAPP, 2014) ou passiva (Pretty, 1995).

Alguns assuntos e problemas do cotidiano são levados pelos conselheiros de ambas as representações para serem discutidos no âmbito do CONDEMA, porém, assim como os questionamentos, essa participação propositiva também é refutada, e por diversas vezes a competência do problema é atribuído a outras instituições, havendo uma indefinição ou entendimento da competência do Conselho Ambiental pelo seus membros, sem que haja uma discussão em torno do problema, um exemplo é o problema relatado por um representante da sociedade civil para ser objeto de discussão do conselho, que teve esclarecimento:

A conselheira [representante da sociedade civil] expôs sobre poluição sonora em área urbana causada por motocicletas as quais veem perturbando o sono e a tranquilidade de moradores daquela área. O presidente esclareceu que o referido problema é de competência da Gerência de Trânsito do Município. O conselheiro [representante do poder público] falou que as medidas adotadas pelo CONTRAN e também sobre a atuação da polícia ambiental, evidenciando que cabe a esta a preocupação com o risco à saúde pública (Ata da Décima Quarta Reunião Ordinária do CONDEMA, linhas 57-63).

Nessa situação observa-se uma indefinição sobre o conhecimento da competência dos membros sobre a poluição sonora, já que o Conselho seria responsável pelo estabelecimento de critérios e normas técnicas de controle da poluição sonora 
(artigo 79) conforme o CMAM, mas como a conselheira não tem conhecimento da legislação aceita a interpelação do Poder Executivo, configurando assim uma participação do tipo persuasiva (Eidsvik, 1978) ou consultiva (Pretty, 1995; IDPP, 2014), em que a consultada acaba seguindo a decisão tomada pela maioria. Além dessa situação específica, diversos outros problemas são levados pelos conselheiros para discussão dentro do CONDEMA, que não estaria dentro de sua competência deliberativa. Esse é um dos outros fatores de problema no processo participativo do conselho: o desconhecimento das competências dos conselheiros e do CONDEMA.

Todas as deliberações das pautas do ano de 2010 são advindas da agenda governamental, enviadas pelos órgãos da administração municipal ou pelo presidente, situação essa que vem a confirmar o caráter legitimador do Conselho das decisões governamentais do município de Mossoró, apresentando uma possível dependência com a gestão pública para o sua existência e funcionamento, se caracterizando como uma participação por persuasão (Eidsvik, 1978) ou consulta (Pretty, 1995; IDPP, 2014).

A frequência de participação dos conselheiros é um componente necessário para efetividade do conselho e sua possível capacidade democratizante. No ano de 2010 ocorreu uma maior proporcionalidade de representação dos participantes da sociedade civil, posto estarem em maioria em quatro reuniões. Essa maior participação da sociedade civil tem referência no conhecimento e maior familiaridade com as reuniões e as próprias continuações das demandas de 2009 , que favoreceu a integração dos representantes desse segmento nas discussões, uma vez que foram formadas diversas comissões e câmara técnicas com a presença dos conselheiros, o que representa a participação funcional (Pretty, 1995) em que é formado grupos para atender aos objetivos predeterminados para uma tomada de decisão, exigindo que os resultados dessas discussões fossem apresentadas e votadas no decorrer do ano, tornando-se um dos fatores que contribuiu para uma maior participação da sociedade civil em relação ao ano anterior.

No ano de 2011 ocorreram seis reuniões ordinárias e duas extraordinárias. Os assuntos das reuniões e as decisões tomadas pelo CONDEMA no ano de 2011 se constituíram como uma continuidade aos posicionamentos dos dois anos anteriores, em que o conselho traz para pauta de decisões assuntos de cunhos estratégicos, as discussões em sua maioria giram em torno de revisão de minutas de leis, resoluções e apresentações de planos de ações de órgãos ambientais do município de Mossoró, e operacionais pelos assuntos administrativos do próprio conselho como escolhas de membros e alterações de regimento interno.

Dentre os assuntos discutidos no CONDEMA em 2011 e a participação dos membros no processo decisório, pode-se destacar a apresentação da Lei Municipal nº 2.678/2010 e Resolução CONDEMA nº 011/2011 sobre a obrigatoriedade das concessionárias de automóveis de plantarem árvores para mitigação do efeito estufa no município de Mossoró, nessa oportunidade um convidado, representante de uma concessionária questionou a finalidade da lei e sugeriu a alteração de alguns trechos, como se vê:

O senhor [nome], representante da concessionária [...], questionou sobre finalidade da Lei, sugerindo alteração ao Parágrafo Primeiro, para inclusão de todas as concessionárias instaladas em Mossoró, ligadas à venda de automóveis, argumentando serem todas estas, fontes emissoras de dióxido de carbono (CO2), complementando ainda que o valor estabelecido em setenta reais por venda de veículo, é insignificante, no entanto há concessionárias que vendem muito acima de cem veículos mensais, o que geraria valores muito altos, e sugeriu revisão destes valores, com a elaboração de nova planilha (Ata da Décima Sexta Reunião Ordinária do CONDEMA, linhas 59-68).

Nesse ponto é importante observar a abertura do CONDEMA para a participação da população e da sociedade produtiva nas reuniões com direito a posicionamento de assuntos ambientais com benefícios coletivos e que afetam atividades e interesses particulares, sem representação dentro do conselho. Havendo essa interação e proximidade de discussão entre os 
interessados nos assuntos do Conselho e os membros, esses últimos externalizando suas considerações e posicionamento no caso.

O conselheiro [representante da sociedade civil] falou sobre a necessidade de inclusão de todas as concessionárias e discordou sobre valor oneroso para concessionárias, quando o presidente completou que esta será também uma forma de marketing para as mesmas (Ata da Décima Sexta Reunião Ordinária do CONDEMA, linhas 73-77).

No caso analisado seis conselheiros presentes na reunião se manifestaram contra a alteração da lei com relação aos valores estipulados, anteriormente questionado e solicitado pelo convidado representante de uma concessionária. A situação em questão direciona o entendimento do conselho como um órgão colegiado e os conselheiros dirimiam e legitimavam os assuntos administrativos que a gestão pública precisava solucionar.

Outra situação de participação dos conselheiros na discussão de minutas de Projeto de Lei, ocorreu na décima oitava reunião ordinária em relação à poluição sonora e a compensação ambiental. No primeiro tema houve solicitação dos conselheiros para alteração de artigos e conceitos dentro do projeto de lei, porém o conflito se acentuou com a questão cultural e religiosa que vinham causando poluição sonora, alguns conselheiros defendiam o estabelecimento de concessões especiais para funcionamentos igrejas:

[O conselheiro representante da sociedade civil] colocou que, assim como qualquer evento, os das igrejas também devem respeitar as leis e desta forma pedir a autorização especial na GGA para realiza-los. [o presidente] concordou e ressaltou que a autorização especial foi um projeto do CONDEMA que virou Lei Municipal, e que de forma alguma é permitido causar poluição sonora. E que não se pode apenas destacar igrejas, mas qualquer evento seja ele cultural ou não. Citou o exemplo do evento cultural municipal, o Mossoró Cidade Junina onde ocorrem muitos shows durante o mês de junho, mas em sua maioria são licenciados. Os eventos não licenciados são cheios de condicionantes definidas em termo de ajustamento de conduta assinado pela Prefeitura e o Ministério Público baseando-se na popularidade do evento a partir de um questionário feito com a população local que em sua maioria aprovou a realização do mesmo (Ata da Décima Oitava Reunião Ordinária do CONDEMA, linhas 98-109, sic).

Os membros que se posicionaram contra a especificação de igrejas dentro da lei de poluição sonora tomaram por base a dificuldade de se chegar ao consenso de todos sobre a questão e por versarem sobre questões culturais e religiosas a lei teria grandes chances de não ser aprovada. Sobre esse assunto, um representante do poder público exemplificou com o veto de um artigo que versava sobre eventos religiosos na Lei Federal no 9.605/98, representando uma participação interativa (Pretty, 1995) ao interagir no processo de tomada de decisão apresentado argumentos na fase de análise que tem sua repercussão e influência no desenvolvimento e definição final da tomada de decisão do projeto de lei.

Ainda na décima oitava reunião do corrente ano foi feita uma proposição de um conselheiro representante da sociedade civil "[...] sobre a maior divulgação do CONDEMA e que possa se aberto espaço para variadas participações e atuações" (Ata da Décima Oitava Reunião Ordinária do CONDEMA, linhas 237-238, sic), em resposta o presidente representante do poder público “[...] esclareceu que após cada reunião é publicada a súmula da reunião no JOM (Jornal Oficial de Mossoró). E quando a participação de visitas externas a mídia é convocada a cobrir o evento" (linhas 238-241).

A limitação da transparência das publicações das reuniões e decisões do CONDEMA, é um ponto a negativo em relação ao conselho, uma vez que seu acesso só é possível in loco. A falta de publicidade e acessibilidade das ações do CONDEMA, é traduzida na pouca divulgação das ações do conselho e no fato de ter que apenas algumas resoluções publicadas no JOM e somente a Súmula da $11^{\text {a }}$ Reunião Ordinária do Conselho Municipal de Defesa do Meio AmbienteCONDEMA foi publicada no JOM publicado em 27 de março de 2010, o que contradiz o discurso do presidente do conselho. 
No que tange à frequência de participação dos conselheiros em 2011. Nesse ano ocorreu maior proporcionalidade de representação dos participantes da sociedade civil, posto estarem em maioria em cinco reuniões e em igualdade em duas. Os assuntos tratados nas reuniões do ano de 2011 podem ser uma justificativa dessa maior participação da sociedade civil, assim como nas reuniões do ano anterior, ocorreram continuações de demandas que integraram de forma mais enfática os representantes dos diversos segmentos nas discussões por se fazerem presentes em comissões e câmara técnicas.

No ano de 2012 ocorreram apenas quatro reuniões ordinárias no CONDEMA. Nesse ano, em três das cinco reuniões os assuntos e decisões tomadas dizem respeito a análise de recurso do Processo Administrativo de infração ambiental. O conselho desde sua criação até o ano de 2012 tem se concretizado como um conselho que tem operacionalizado as demandas da gestão pública evidenciando-se uma atuação do tipo persuasivo (Eidsvik, 1978) ou consultivo (Pretty, 1995; IDPP, 2014), por vezes tem se assemelhado a órgãos ou tribunais julgadores de procedimentos administrativos se distanciando de características propositivas, fiscalizadoras e orientadoras em prol da defesa e promoção do meio ambiente que a lei de criação determina.

Nesse quadriênio poucas são as ações operacionais de atuação do conselho, sua atuação tem se pautado na resolutividade dos assuntos da gestão e a participação dos membros tem se limitado a legitimar as propostas governamentais, a figura do presidente do conselho é a protagonista em todas as reuniões desse período e o fato da função ser ocupada pelo secretário/gerente do órgão administrativo municipal de meio ambiente talvez seja uma das motivaçães para a atuação do conselho ser centralizada somente assuntos de interesse da gestão e na justificativa dos problemas da gestão ambiental levados ao conselho pelo presidente. Nesse sentido a capacidade propositiva dos representantes sociais são limitadas, pois as pautas das reuniões são eminentemente prerrogativa da gestão do poder executivo, o que configura na tipologia de persuasão (Eidsvik, 1978) ou consultivo (Pretty, 1995; IDPP, 2014).

A pouca divulgação das ações e das reuniões do CONDEMA talvez seja uma forma de proteção da pressão populacional dentro do conselho por parte da gestão. Essa limitação do conhecimento da população mossoroense e ausência de transparência sobre as ações do CONDEMA pode ser percebida na situação ocorrida na Vigésima Quinta Reunião Ordinária, quando uma "[...] participante da reunião, sugeriu que fosse realizado maior divulgação das reuniões. [O presidente] explicou a forma de divulgação das reuniões, que são através de e-mail e ligações" (linhas 68-70), o que demostra uma ausência de interesse nas discussões públicas sobre o que ocorre dentro do CONDEMA, acarretando o problema da transparência dos atos do conselho para a sociedade externa.

No ano de 2012 ocorreu uma maior proporcionalidade de representação dos participantes do poder público em todas as reuniões do ano, possíveis justificativas para essa situação podem estar ligadas aos assuntos específicos e extremamente técnicos das pautas, como o julgamento de procedimentos administrativos, o poder de mobilização fora do conselho dos representantes do Poder Público e a existência obrigacional de participação dos funcionários da prefeitura para aprovação de assuntos de interesse da gestão.

\subsubsection{Período 2013-2015}

O segundo período de análise é compreendido entre os anos de 2013 a 2015, nesse período houve uma mudança na gestão municipal em virtude da cassação da gestora eleita nas eleições regulares de 2012, no final do primeiro ano de seu mandato foi realizada eleição suplementar assumindo outro gestor até o ano de 2016.

No ano de 2013 foram realizadas três reuniões ordinárias e uma extraordinária. A atuação do CONDEMA no ano de 2013 esteve centrada na sua formação e composição, apresentação de plano de trabalho do Conselho e novamente a formação de mais uma comissão para avaliação ou modificação do Regimento Interno. As discussões ambientais representativas ocorreram na vigésima oitava reunião ordinária com uma participação informativa (Eidsvik, 1978; IAPP, 2014) por meio de 
palestras e esclarecimentos de alguns assuntos. A atuação do conselho nesse ano em grande parte assumiu um papel operacional, uma vez que as decisões tomadas são assuntos burocráticos do próprio Conselho.

A maior proporcionalidade de representação nesse ano foi de participantes da sociedade civil em três reuniões, a possível justificativa para essa situação possivelmente são os assuntos tratados nas reuniões relacionado a estruturação do Conselho e a mudança dos conselheiros, uma vez que esses novos representantes se apresentam com mais ânimo para atuação, além da afinidade com a área ambiental.

Todas as reuniões desse ano trataram de assuntos propostos pela gestão relacionados aos julgamentos de recursos de processos administrativos de infrações ambientais. O Conselho se apresentou como um órgão julgador de demandas administrativas da gestão, de participação persuasiva (Eidsvik, 1978) ou consultiva (Pretty, 1995; IDPP, 2014), embora fosse competência do CONDEMA julgar esses processos, eles tendem a desviar a função principal do Conselho e contribuir para o seu esvaziamento.

Nesse ano apenas uma decisão político-estratégica surgiu no âmbito do CONDEMA, trata-se o caso da região que tomou repercussão nacional, da proposta de um promotor de justiça de inserir a carne de jumento (Equus asinus) na alimentação de presos do Estado do Rio Grande do Norte (Gibson, 2014). Um conselheiro representante da sociedade civil propôs que o assunto entrasse na pauta do conselho. Houve uma palestra sobre a temática e posteriormente os conselheiros decidiram elaborar um texto apresentando os pontos positivos e negativos do abate desses animais. Nessa ação o conselho atuou de forma propositiva e assume um tipo de participação de controle (Eidsvik, 1978), participação interativa (Pretty, 1995) ou de Emponderamento ou delegação (IAPP, 2014).

As demais ações dos conselheiros no processo decisório e na atuação do CONDEMA embora sejam de caráter estratégico, apresentaram-se como uma participação de consulta (Eidsvik, 1978), funcional (Pretty, 1995) ou colaborativa (IAPP, 2014).

Nesse ano houve uma predominância na igualdade de proporcionalidade de representação, porém em relação às frequências dos outros anos constata-se uma diminuição da participação de ambos os segmentos. Esse esvaziamento do conselho pode estar relacionado à pauta de discussões que passou as ser predominantemente de julgamento de infrações ambientais, cujo nível de conhecimento técnicos e linguagem especializada pode ser um fator que compromete o processo participativo e decisório, uma vez que tendem a gerar assimetrias de poder, pois os técnicos detém maior influência nas deliberações, no caso dos Conselhos Ambientais, a representatividade de técnicos ligados ao poder público tendem a ser maior (Giaretta, Fernandes, \& Philippi Jr., 2012; Fonseca, Bursztyn \& Moura, 2012).

O CONDEMA atuou no ano de 2015 apenas em uma única reunião ordinária com todos os membros do conselho para mudança no seu quadro de conselheiros, ocorrido bienalmente, portanto a participação esteve centrada na formação de mais uma comissão para avaliação ou modificação da composição e do Regimento Interno. As discussões ocorridas no âmbito do conselho tiveram uma característica de participação informativa (Eidsvik, 1978; IAPP, 2014), assumindo o conselho nesse ano um papel operacional.

A trigésima quinta reunião ordinária da comissão foi a última sessão do CONDEMA, após essas suas atividades ficaram paralisadas, visto a dependência do Conselho em relação a gestão do município para o seu funcionamento, dentre os fatores estão a centralização do Conselho na figura do presidente, função ocupada pelo secretário de infraestrutura e meio ambiente de Mossoró, a falta de espaço próprio e retardamento pelo chefe do executivo e do poder legislativo na promulgação no regimento interno e alterações legislativas do Conselho, publicado apenas no Jornal Oficial de Mossoró (JOM) n 363 , do dia 01 de julho de 2016, por meio do Decreto nº 4.959, de 16 junho de 2016. 
Em 2015 apenas a trigésima terceira reunião ordinária houve a participação dos conselheiros, em virtude da eleição e nomeação para o mandato no conselho e a formação de uma comissão para alterar o regimento do conselho. Assim, as reuniões seguintes foram feitas apenas com os membros que estavam compondo a comissão para alteração do documento.

Nesse quadriênio não existiu uma continuidade e uniformidade de proporcionalidade de representação, ao passo do tempo a participação dos conselheiros foi se esvaziando. Se analisarmos desde sua formação em 2009 até o ano de 2015, ao compararmos os dois quadriênios vê-se que há uma dependência do conselho com o poder público para a realização das reuniões e o seu andamento, nesse último a instabilidade na gestão pública pela mudança do chefe do executivo afetou os trabalhos do CONDEMA, pois o presidente do conselho é o próprio secretário da pasta do meio ambiente do município, que por sua vez depende da nomeação do prefeito.

O CONDEMA, nos dois períodos de existência, assumiu na maioria dos anos uma atuação com característica estratégica no processo de tomada de decisão, porém é importante abordar que embora sejam decisões estratégicas para o meio ambiente, grande parte da atuação do Conselho se restringiu a atividades de apreciação e criação de normas e julgamento e recolhimento de taxas e multas ambientais, ainda que seja competência do conselho atuar nesse sentido, "[...] o foco nas atribuições técnicas e burocráticas nos conselhos gestores impede que os mesmos possam agir na definição estratégica de rumos das políticas públicas" (Fonseca, Bursztyn \& Moura, 2012, p. 186).

Nesse mesmo sentido, Acselrad (1996) e Cohn (2009), conforme abordado no subitem anterior, os conselhos tem se tornado um verdadeiro órgão de produção normas e de julgamento de infrações ambientais, perdendo a essência primordial do elo entre Estado e sociedade, para contemplar somente os anseios governamentais, ao tratar de assuntos específicos e técnicos pouco se relacionando com o pensamento político-estratégico esperado dessas arenas democráticas.

Nesses dois períodos predominou a participação de consulta (Eidsvik, 1978; IAPP, 2014) ou funcional (Pretty, 1995), visto as grandes quantidades de pautas que eram propostas pelo presidente e o governo municipal. Sobre as frequências de participação nas reuniões a sociedade civil teve maior proporcionalidade de representação nesses dois períodos.

\section{Considerações Finais}

$\mathrm{Na}$ dimensão formal observou-se nas atas de reuniões que as deliberações do CONDEMA foram eminentemente de assuntos que respondiam a demandas da Administração do município. A atuação dos conselheiros nessa dimensão se restringiu predominantemente a uma participação de consulta (Eidsvik, 1978, Pretty, 1995, IAPP, 2014), persuasão (Eidsvik, 1978) ou funcional (Pretty, 1995).

Embora a sociedade civil tenha tido maior representatividade nas reuniões, as decisões foram conduzidas pelos membros do poder público, pois a maioria das pautas foram propostas pelo presidente do conselho ou pelo governo municipal, constituindo um dos problemas para efetivação de uma participação ideal, visto que as reuniões assumiram um caráter quase sempre deliberativo sem espaços de reflexão e formulação de propostas por parte do Conselho.

Outros fatores impeditivos para a participação foram a grande quantidade de pautas com assuntos técnicos, como o julgamento de autos de infrações, ao tratar de assuntos específicos e técnicos pouco se relacionando com o pensamento político-estratégico esperado dos Conselhos.

Ainda que se faça necessário a participação popular na defesa ambiental e por conseguinte a importância de uma atuação ativa dos Conselhos como uma potencialidade democrática na gestão pública local, o funcionamento interno e externo desses espaços encontram limitações que repercutem no modus operandi das decisões tomadas.

É o que se observou na dimensão formal, e que foi detalhado pela visão dos conselheiros. O CONDEMA apresentou alguns problemas apontados pelos conselheiros que precisam ser fortalecidos em seu processo participativo, pois tem prejudicado a atuação dos conselheiros de forma que proporcione uma participação ideal (Garbeline, 2017). 
Porém, é possível encontrar nas atas alguns momentos de participação dos tipos de parceria (EIDSVIK, 1978), interativa (Pretty, 1995) ou colaborativa (IAPP, 2014) com o papel atuante do CONDEMA, com destaque para produções de normas ambientais que modificam o comportamento social como a "Lei dos Paredões" surgida no âmbito dos conselhos, mudanças nas atividades empresariais com a proposição de lei que obrigava a plantação de mudas pelas concessionárias de automóveis, e ainda, colaboração para criação e proteção ambiental de nível e repercussão nacional como a criação do Parna da Furna Feia e a defesa do jumento (Equus asinus).

Os resultados da pesquisa corroboram com aqueles apresentados por Morais et al (2018) que ao analisar a percepção de participação de conselheiros do CONDEMA identificou uma tendência a uma participação legitimadora das açães do poder público municipal.

Estudos futuros poderiam abordar uma análise comparativa de outros Conselhos a fim de identificar se a estrutura dessa instância de participação no âmbito ambiental tem características singulares que dificultam um processo decisório mais equilibrado ou se essa é uma realidade em Conselhos de outras temáticas.

Outra possibilidade seria uma análise das pautas dos movimentos ambientais da região e como essas são acolhidas ou não pelos Conselhos Municipais, a fim de compreender como a dinâmica de participação da sociedade civil se amplia ou não considerando os movimentos organizados.

\section{Agradecimentos}

O presente trabalho foi realizado com apoio da Coordenação de Aperfeiçoamento de Pessoal de Nível Superior Brasil (CAPES) - Bolsa de Mestrado Stricto Sensu

\section{Referências}

Acselrad, H. (1996). Política ambiental e discurso democrático. O caso do Conselho Nacional de Meio Ambiente. Trabalho apresentado no XX Encontro Anual da Associação Nacional de Pós-Graduação e Pesquisa em ciências sociais, realizado em Caxambu (Minas Gerais).

Brasil. (2020). Constituição da República Federativa do Brasil: texto constitucional promulgado em 5 de outubro de 1988, compilado até a Emenda Constitucional no 106/2020. Brasília: Senado Federal, Coordenação de Edições Técnicas, 2020.

Brasil. (2012). Decreto sem número de 05 de junho de 2012. http://www.planalto.gov.br/CCIVIL_03/_Ato2011-2014/2012/Dsn/Dsn13320.htm.

Carvalho Filho, J. S. (2020). Manual de Direito Administrativo. (34a ed.), Atlas.

Creswell, J. W. (2010). Projeto de pesquisa: métodos qualitativo, quantitativo e misto. ARTMED.

Cohn, A. (2009). A reforma sanitária brasileira após 20 anos do SUS: reflexões. Caderno de Saúde Pública. 25(7), 1614-1619.

Cotta, R. M. M., Cazal, M. M., \& Rodrigues, J. F. C. (2009). Participação, Controle Social e Exercício da Cidadania: a (des)informação como obstáculo à atuação dos conselheiros de saúde. Physis. 19(2), 419-438.

Eidsvik, H. K. (1978). Involving the public in park planning: Canada. Parks. 2(1), 3-5.

Fonseca, I. F., Bursztyn, M., \& Moura, A. M. M. (2012). Conhecimento técnicos, políticas públicas e participação: o caso do conselho nacional de meio ambiente. Revista de Sociologia e Política. 20(42).

Garbeline, C. B. (2017). Reflexão sobre participação social: barreiras e estratégias. Geosul, Florianópolis, $32(64), 165-178$.

Giaretta, J. B. Z., Fernandes, V., \& Philippi Jr. (2012). A. Desafios e condicionantes da participação social na gestão ambiental municipal no Brasil. Organizações \& Sociedade, 19(62), 527-548.

Gibson, F. (2014). Promotor propõe carne de jumento na alimentação de presos do RN. Portal G1 do RN. Natal, RN. Publicado 07/03/2014. http://g1.globo.com/rn/rio-grande-do-norte/noticia/2014/03/promotor-propoe-carne-de-jumento-na-alimentacao-de-presos-do-rn.html.

IDEMA. (2015). Instituto de Desenvolvimento Econômico e Meio Ambiente do Rio Grande do Norte. Projeto SISMUMA. Relatório parcial do diagnóstico sobre os Sistemas Municipais de Meio Ambiente do Estado do Rio Grande do Norte. [Não Publicado]. Natal.

International Association for Public Participation (IAPP). (2014). The IAP2 Public Participation Spectrum. 2014. https://www.iap2.org.au/wpcontent/uploads/2019/07/IAP2_Public_Participation_Spectrum.pdf.

Matias-Pereira, J. (2016). Manual de gestão pública contemporânea. (5a ed.), Atlas. 
Research, Society and Development, v. 10, n. 5, e19910515079, 2021

(CC BY 4.0) | ISSN 2525-3409 | DOI: http://dx.doi.org/10.33448/rsd-v10i5.15079

MDA. (2014). Ministério do Desenvolvimento Agrário (MDA). Sistema de Informações Territoriais. Território Açu-Mossoró-RN. 〈http://sit.mda.gov.br〉.

Morais, L. A. (2017). Conselhos Ambientais: Uma análise do processo de participação de conselheiros municipais no Território Açu-Mossoró-RN. $204 \mathrm{f}$. Dissertação (Mestrado) - Curso de Pós-graduação em Ambiente, Tecnologia e Sociedade, Universidade Federal Rural do Semi-Árido, Mossoró.

Morais, L. A., Siqueira, E. S., Cabral, L. C. G., \& Siqueira Filho, V. (2018). Conselhos Ambientais: Dinâmicas de participações de conselheiros municipais no Território Açu-Mossoró-RN. In: XX Encontro Internacional de Gestão Empresarial e Meio Ambiente. - ENGEMA, Dezembro 2018, São Paulo, SP. Anais (online).

Nunes, M. R., Philippi Jr, A., \& Fernandes, V. (2012). A Atuação de conselhos do meio ambiente na gestão ambiental local. Saúde Sociedade. 21(3), 48-60.

Pereira, N. R., Lima, A. A. T. F. C., \& Martins, S. (2013). Contribuições de estudos brasileiros sobre os conselhos de políticas públicas como instância legítima do processo decisório na administração. In: Ferreira, M. A. M., Abrantes, L. A.(Org.). Políticas públicas, gestão e sociedade. Viçosa: Triunfal Gráfica e Editora.

Pretty, J. N. (1995). Participatory learning for sustainable agriculture. World Development. 23(8), 1247-1263.

Rosenfield, D. L. (2003). O que é democracia. Brasiliense.

Severino, A. J. (2013). Metodologia do trabalho científico. Cortez.

Soares, J. A. (1992). Poder local e participação popular. Rio Fundo Ed.

Souza, D. B., \& Novicki, V. (2011). A Participação Social na Questão Ambiental: limites e possibilidades nos conselhos de meio ambiente no Brasil. Meta: Avaliação. 3(7), 25-40.

Souza, D. B., \& Novicki, V. (2010). Conselhos municipais de meio ambiente: estado da arte, gestão e educação ambiental. Liber Livro.

Vergara, S. C. (2016). Projetos e relatórios de pesquisa em administração. Atlas. 